\title{
Diagnosis and treatment of infection with Brucella abortus, biotype 5
}

\author{
L. ROBERTSON
}

From the Public Health Laboratory, Royal Infirmary, Preston

SYNOPSIS A case of brucellosis due to Brucella abortus, biotype 5, occurred in a bulk milk-tanker driver who collected milk from refrigerated tanks on 23 farms.

The organism was isolated from blood cultures by using a serum dextrose broth containing antibiotics. Serological investigations indicate that both abortus and melitensis antigen suspensions should be used in the investigation of cases of suspected brucellosis.

As Brucella abortus is an intracellular parasite heavy, prolonged, antibiotic therapy is necessary in the treatment of the disease. The danger of inadequate treatment of the acute disease is that it may become chronic, and response to antibiotic therapy in chronic brucellosis is not good.

Five of the nine biotypes of Brucella abortus described by the W.H.O./F.A.O. Expert Committee on Brucellosis (Report, 1964a) have been isolated from dairy herds in Lancashire, in which county there are approximately 1,500 farmers selling raw milk directly to the public. At least $20 \%$ of their herds have been shown to be infected with Brucella abortus (Robertson, 1961; Report, 1964b) and the frequency of the biotypes isolated during 1964 was: biotype $1,79 \%$; biotype $2,15 \%$; biotype $4,0.4 \%$; biotype $5,7 \%$; biotype $9,5 \%$. Some herds were infected with two or three biotypes.

Brucella abortus, Brucella melitensis, and Brucella suis are the three Brucella species that cause human disease but, so far, only Brucella abortus has been isolated in this country. Cattle are the reservoir from which man is infected by drinking raw milk or raw cream, or by occupational contact, e.g., the farming community, veterinary surgeons, abattoir workers, and dairy employees.

The W.H.O./F.A.O. Expert Committee on Brucellosis (Report, 1964a) summarized the new classification of the Brucella genus. The three species are subdivided into nine abortus, three melitensis, and three suis biotypes. The basis of the subdivision is, first, the reaction of the organisms to oxidative metabolic tests where the three species give a constant and distinct pattern from one another, and, secondly, the reaction of the three species to abortus bacteriophage to which only the nine biotypes of Brucella abortus are susceptible. These two basic differences, which differentiate the three species, are shown in Table $I$.

Received for publication 24 October 1966.
The biotypes of Brucella abortus are distinguished from each other by their carbon dioxide dependence, production of hydrogen sulphide, growth on dyecontaining media, and their reaction to monospecific abortus and monospecific melitensis sera. From Table $I$ it can be seen that an organism is called Brucella abortus because of its oxidative metabolic activities on the four substrates and because it is lysed by the abortus bacteriophage, and Table II shows that such an organism can possess the conventional biochemical and serological characters of either 'abortus' or 'melitensis' and may be either dye-sensitive or dye-resistant. Nine abortus biotypes have been described, having different combinations of these three basic characteristics.

\section{TABLE I}

DIFFERENTIATION OF THE THREE SPECIES OF BRUCELLA

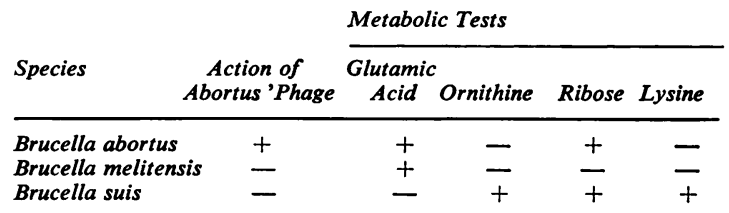

The biochemical and serological classification of the biotypes of Brucella abortus isolated from cattle in Lancashire is presented in Table II, which also includes Brucella abortus, biotype 1, and Brucella suis, biotype 1 , for comparison with the abortus biotypes.

Biotype 5 is the organism that used to be called 'British melitensis' as it gives the biochemical, 
TABLE II

BIOCHEMICAL AND SEROLOGICAL CLASSIFICATION OF THE BIOTYPES OF BRUCELLA ABORTUS ISOLATED FROM CATTLE IN LANCASHIRE

\begin{tabular}{|c|c|c|c|c|c|c|c|c|}
\hline \multirow[t]{2}{*}{ Species } & \multirow[t]{2}{*}{ Biotype } & \multirow{2}{*}{$\begin{array}{l}\mathrm{CO}_{2} \\
\text { Requirements }\end{array}$} & \multirow{2}{*}{$\begin{array}{l}\mathrm{H}_{2} \mathrm{~S} \\
\text { Production }\end{array}$} & \multicolumn{2}{|c|}{ Growth on Dyes } & \multicolumn{2}{|c|}{$\begin{array}{l}\text { Agglutination with } \\
\text { Monospecific Sera }\end{array}$} & \multirow[t]{2}{*}{ Remarks } \\
\hline & & & & Thionin & Basic Fuchsin & Abortus & Melitus & \\
\hline \multirow[t]{6}{*}{ Brucella abortus } & 1 & + & + & - & + & + & - & \multirow{8}{*}{$\begin{array}{l}\text { Typical abortus } \\
\text { Dye sensitive } \\
\text { Abortus bio- } \\
\text { chemical and } \\
\text { melitensis sero- } \\
\text { logically } \\
\text { As } 4(\text { a) but dye } \\
\text { sensitive } \\
\text { British melitensis } \\
\text { Similar to British } \\
\text { melitensis but } \\
\text { produces } \mathrm{H}_{2} \mathrm{~S}\end{array}$} \\
\hline & 2 & + & + & - & - & + & 一 & \\
\hline & 4a) & + & + & - & + & - & + & \\
\hline & 4(b) & + & + & 一 & - & - & + & \\
\hline & 5 & - & - & + & + & - & + & \\
\hline & 9 & - & + & + & + & 一 & + & \\
\hline Brucella melitensis & 1 & 一 & - & + & + & - & + & \\
\hline Brucella suis & 1 & - & + & + & - & + & - & \\
\hline
\end{tabular}

serological, and dye-sensitive characteristics of Brucella melitensis, biotype 1, except that it is lysed by abortus bacteriophage and gives the oxidative metabolic reactions of Brucella abortus (Table II).

In the United Kingdom, because we are dealing only with Brucella abortus, the diagnosis of human brucellosis is usually made by the finding of a high antibody titre in the blood, and, much less frequently, by the isolation of the organism from the blood. Because of the lower isolation rate we have no exact knowledge of the pathogenicity of the biotypes of Brucella abortus for man or of the extent of human infection by any one of them.

The purpose of this paper is to describe a case of brucellosis due to Brucella abortus, biotype 5, demonstrating the importance of blood cultures containing antibiotics, and the use of both abortus and melitensis antigens in the diagnosis of brucella infections. The essential points of treatment are also emphasized.

\section{CASE REPORT}

A bulk-milk-tanker driver, aged 36 years, collected milk from 23 Lancashire farms during the day. He came into contact with raw milk when he coupled the milk-tanker to the refrigerated storage tanks on the farms, when he took daily samples from each of the storage tanks for the routine chemical and bacteriological examinations to be carried out by the dairy laboratory, and when he cleaned out the milk tank. In addition, he drank raw milk on the farms, especially during the hot weather. His family drink pasteurized milk.

He consulted his doctor because of an indefinite illness characterized by tiredness, malaise, and night sweats; these symptoms had been present for about a month. He had been taking his temperature and noted that it was normal in the morning but that he had an evening temperature of $101-102^{\circ} \mathrm{F}$.
On enquiry, he admitted to bouts of gastritis and enteritis during the past three or four months.

On examination he appeared well and was wellnourished. There was no lymphadenopathy or rash. The only positive finding was an enlarged spleen extending three fingerbreadths below the costal margin; it was firm, but not tender, and was still palpable two months later.

$\mathrm{He}$ attended the Out-patient Department during the morning when he was afebrile, and the following investigations were made:

Haemoglobin was $13.2 \mathrm{~g} .100 \mathrm{ml}$. $(88 \%)$, white blood cells, 3,400/c.mm. (polymorphs $49 \%$, lymphocytes $42 \%$, monocytes $4 \%$, eosinophils $3 \%$ ) plasma cells $2 \%$. The E.S.R. was $24 \mathrm{~mm}$. in the first hour (Wintrobe, corrected). The alkaline phosphatase level was 34 units $/ \mathrm{ml}$.

Urine examination showed $100 \mathrm{mg}$. albumin/100 ml., and a few granular casts.

Culture of throat swabs and faeces did not reveal any pathogenic organisms. The Paul Bunnell test was negative at a dilution of $1: 10$.

There was no serological evidence of infection with organisms of the enteric group.

The agglutination titre to Brucella abortus was $<1: 30$.

A blood culture was made in brain infusion broth (Oxoid) and incubated aerobically at $37^{\circ} \mathrm{C}$. It was not incubated in an atmosphere of carbon dioxide as a brucella infection was not considered.

After two days' incubation the blood culture was subcultured to a blood agar plate, which was incubated aerobically at $37^{\circ} \mathrm{C}$; a small, Gram-negative bacillus was isolated which gave a positive slide agglutination reaction with Brucella abortus antiserum. It had the biochemical and serological characteristics of biotype 5, and was lysed by abortus bacteriophage. With the knowledge of this isolation the agglutination titre to Brucella melitensis was determined and was found to be 1:240, on the same serum specimen that had shown a titre of $<1: 30$ to Brucella abortus,

The raised alkaline phosphatase, albuminuria, and the presence of casts in the urine probably reflected the liver and kidney involvement in a generalized infection. 
The patient was admitted to hospital and responded well to antibiotic therapy. The course of treatment was $1 \mathrm{~g}$. tetracycline twice a day for three weeks, a week off treatment, and then another three weeks' tetracycline, a total of $84 \mathrm{~g}$. of tetracycline over a seven-week period. Because Brucella abortus is an intracellular parasite the tetracycline therapy was given in high dosage over a prolonged time. The tetracycline dosage was divided into two three-weekly periods, so that the second half of the treatment could affect those organisms that had been intracellular and not killed during the first half. During the first week of treatment he was given $1 \mathrm{~g}$. of streptomycin intramuscularly, each day, in addition to the tetracycline. By the end of the fourth day of treatment the patient had become objectively and subjectively better. Because of this improvement it was decided to stop the streptomycin at the end of the week for there was a risk of renal damage as albumin and casts had already been found in the urine, and, in addition, there was the possibility of damage to the eighth cranial nerve if the streptomycin therapy was prolonged.

It was thought expedient to discharge him from hospital two weeks after admission and to continue the treatment at home because of the danger of superinfection of the gastrointestinal tract with a hospital strain of antibiotic-resistant Staph. aureus in a patient receiving a heavy daily dose of tetracycline, an antibiotic which is known to upset the gastrointestinal flora.

He made a slow, but uninterrupted, recovery and restarted work 15 weeks after he first consulted his general practitioner. The duration of the illness was at least 19 weeks. He has remained well for a year and has not had a relapse.

\section{RESULTS OF LABORATORY INVESTIGATIONS}

After admission to hospital a second isolation of the organism was made in serum-dextrose broth containing antibiotics.

Seven samples of serum were taken during the patient's illness, convalescence, and after his return to work. These were titrated against Brucella abortus and Brucella melitensis suspensions, and a suspension of the homologous organism. The antibody titres to these three suspensions are presented in Table III showing that although the abortus anti-

TABLE III

SERUM AGGLUTINATION TITRES AGAINST BRUCELLA ABORTUS AND BRUCELLA MELITENSIS STANDARD SUSPENSIONS AND A SUSPENSION OF THE HOMOLOGOUS ORGANISMS (BRUCELLA ABORTUS, BIOTYPE 5)

\begin{tabular}{rrrr} 
& Brucella abortus & Brucella melitensis & $\begin{array}{c}\text { Homologous Organism } \\
\text { (Biotype 5) }\end{array}$ \\
\hline 30 Sept. & $<30$ & 240 & 240 \\
13 Oct. & 30 & 960 & 960 \\
2 Nov. & 960 & 960 & 1,920 \\
23 Nov. & 480 & 960 & 960 \\
15 Feb. & 120 & 240 & 480 \\
7 May & 30 & 60 & 60 \\
17 Sept. & $<30$ & 30 trace & 30 trace
\end{tabular}

bodies appeared later they nevertheless reached the same titre as the melitensis antibodies.

The progressive fall in antibody titres since clinical recovery probably indicates that the disease is no longer active, and the last serum, taken a year after the disease was diagnosed, showed the absence of antibodies to Brucella abortus at a dilution of 1 in 30 , while there was still a trace of agglutination to both Brucella melitensis and the homologous organism.

The haematological investigations showed that the haemoglobin, which was $80 \%(11.8 \mathrm{~g}$.$) at the$ height of the disease, began to recover towards normal and had done so two months later, when the haemoglobin was $97 \%(14.2$ g.). The E.S.R. (Wintrobe), which was $24 \mathrm{~mm}$. in the first hour at the first examination, had fallen to within normal limits within six weeks. However, in cases of brucellosis the E.S.R. is often within normal limits or only slightly raised throughout the illness. The more significant finding was a persistent neutropaenia which is a common finding in brucellosis: the first white cell count was 3,400 per c.mm. $(46 \%$ polymorphs) and nine months later the white count was still only 4,600 per c.mm. ( $43 \%$ polymorphs).

\section{DISCUSSION}

The first isolation in the United Kingdom of the organism now called Brucella abortus, biotype 5, was made in 1940 from a dairy herd. The organism had the biochemical and serological characteristics of Brucella melitensis and therefore it was thought to be a true 'melitensis' strain. Experience in other countries has shown that infection with true Brucella melitensis is a more serious threat to human health and causes a more severe economic loss to the agricultural industry than Brucella abortus, an organism which for many years had been known to be widespread among the dairy herds. For this reason the Brucella melitensis Order of $1940 \mathrm{em}$ powered the compulsory slaughter of infected animals. Subsequent experience showed that this organism did not have the pathogenicity of true Brucella melitensis, as there was no evidence of spread to the human population, no increase in the number of abortions among cattle, and no spread to sheep or goats, the natural hosts of Brucella melitensis. Over the years the Order fell into disuse and in 1956 it was suspended; each case of infection in animals was to be decided on its merit at the discretion of the local veterinary officer. The organism came to be known as 'British' melitensis, whereas its oxidative metabolic activity and sensitivity to bacteriophage shows that it is an abortus biotype. The fact that it is an abortus biotype 
probably accounts for its low pathogenicity for both man and animal.

The only previous report of human infection with biotype 5 in this country has been made by Barrow and Peel (1965). They record a case of infection in a schoolboy, aged 12 years, where the diagnosis was made by the isolation of the organism from the blood on two separate occasions. The boy was infected by the occasional drinking of raw infected milk from a dairy and the organism was isolated from several cows in the herd.

The diagnosis of infection with Brucella abortus is more often made by the demonstration of serum agglutinins than by the isolation of the organism from the patient. Dalrymple-Champneys (1960) reported a series of 439 cases where isolation of the organism by blood culture was attempted, but was successful in 71 cases $(15.2 \%)$ only.

On the other hand, Huddleston (1943) states that when the infection is due to either Brucella melitensis or Brucella suis there is little difficulty in obtaining a positive blood culture during a pyrexial phase. In patients infected with Brucella abortus there are fewer organisms in the blood. Because of this, $30-40 \mathrm{ml}$. of venous blood should be withdrawn from the patient and distributed among a series of blood culture bottles, and it is not unusual to find only one or two of them showing a positive result (Spink, 1956a).

Because of past experience of the low isolation rate from blood culture it is seldom used as a method of diagnosis and greater reliance is placed on serological investigation. However, if serological methods alone are used a number of infections will be missed, as cases have been reported where the organism has been isolated from the blood in the absence of any serological response (Evans, 1934; Spink, 1956b).

When the patient was seen at the Out-patient Department the possibility of brucella infection was not considered and therefore the first blood culture was not incubated in the presence of carbon dioxide. However, the organism isolated, biotype 5, does not require the presence of carbon dioxide for growth, nor do two other biotypes which could infect man in this part of the country, biotype 4, which is melitensis biochemically and abortus serologically, and biotype 9, which differs from biotype 5 only in the production of hydrogen sulphide during growth (Table II). The biotypes which do not require the presence of carbon dioxide for growth are present in $12 \%$ of the infected herds in Lancashire whose raw milk is sold to the public. The remaining $88 \%$ of the infected herds are infected with biotypes which require the presence of carbon dioxide for growth.
Therefore, when a brucella infection is suspected it is necessary to incubate blood cultures in an atmosphere with added carbon dioxide. The required atmosphere of carbon dioxide, which should be between 20 and $30 \%$, is obtained by placing the cultures in an anaerobic jar, exhausting the required amount of air and replacing it with carbon dioxide.

A number of selective agars have been developed for the cultural isolation of brucella organisms from milk, and some of these agars make use of the fact that brucella organisms are not inhibited by low concentrations of polymyxin, bacitracin, or actidione. When brucella infections are suspected, or in a clinical case of pyrexia of unknown origin in patients who either drink raw milk or are in occupational contact with cattle, it is suggested that two blood cultures should be set up, one in nutrient broth for the isolation of organisms other than brucellae, and the other in a broth containing antibiotics for the isolation of brucella organisms. Using antibiotic broths isolates have been made from clinical cases by Barrow and Peel (1965), and in one case investigated in this laboratory, when biotype 1 was isolated after three weeks' incubation from a farmer presenting with an influenzal-like illness.

The blood culture medium should have as a basis a good bacteriological broth that is known to support the growth of Brucella abortus; this particularly applies to liver broth, batches of which have been shown not to support the growth of the organism. The suggested media are either a fluid Mair's medium (Mair, 1955) or a serum dextrose broth containing bacitracin 10 units $/ \mathrm{ml}$., polymyxin 4 units $/ \mathrm{ml}$., actidione $0.001 \mathrm{mg} / \mathrm{ml}$., $5 \%$ horse serum, $1 \%$ glucose. The only disadvantage of Mair's medium is in its content of gentian violet and penicillin, both of which inhibit the growth of the dye sensitive organisms, biotype 2 (Wilson, 1933) and a dye-sensitive variant of biotype 4 .

The value of these broths is that frequent subcultures can be made without the hazard of contamination to which all blood cultures are liable. It is suggested that blood cultures should be subcultured twice a week for at least eight weeks before a negative result is issued.

One of the reasons for the failure to isolate Brucella abortus from blood is the possibility of a brucella infection not being appreciated during the investigation of cases eventually diagnosed as acute or chronic brucellosis; sometimes weeks elapse before the possibility of brucellosis is considered. In addition, the onset of the disease is often insidious and weeks or months may elapse before the patient seeks medical advice. Eventually there is either an acute episode, or the patient gradually becomes aware of a perpetual state of ill health, 
and by the time blood cultures are made the organism is lodged in the reticulo-endothelial system and is infrequently present in the peripheral blood.

This intracellular situation of the organism is responsible for the difficulty of antibiotic treatment, as the soluble antibiotics seem to be incapable of penetrating the cell membrane in adequate concentration (Castenada and Carrillo-Cardenas, 1953).

Tetracycline is the antibiotic of choice and the relapse rate is less when tetracycline and streptomycin are given together (Eisele and McCullough, 1947; Spink, Hall, Shaffer, and Braude, 1948; Debono, 1949; Castenada and Ibarra, 1952; Knight, 1950; Knight, Ruiz-Sanchez, and McDermott, 1950).

Success in treatment depends on persevering with heavy, prolonged, antibiotic therapy in patients who have responded quickly to antibiotics, both subjectively and objectively, and usually within a week. The danger of inadequate treatment of an acute case is that the disease may become chronic, and in chronic brucellosis the response to therapy is not good.

The serological results obtained from this patient (Table III) correspond with the results obtained in experimental animals where in the early stages of infection with biotypes 4,5 , and 9 melitensis agglutinins are present before the abortus ones. In this case, if the blood culture had been negative, or had not been done, the melitensis agglutinins would not have been titrated and the diagnosis of the disease would have been delayed by about a month, because the second serum, taken a fortnight after the first, showed an abortus titre of only 1 in 30 , while the melitensis titre was 1 in 960 (Table III).

The Standards Laboratory of the Public Health Laboratory Service issues four times more Brucella abortus than Brucella melitensis suspension (Bradstreet, 1965) and this suggests that most laboratories in the United Kingdom do not test for melitensis antibodies as a routine.

These results indicate the necessity to use both abortus and melitensis antigens in the agglutination tests when testing sera from patients with suspected brucellosis.

I wish to thank Dr. D. M. Anderson, consultant physician, Preston Royal Infirmary, for access to the clinical notes and to the patient; Dr. A. A. Miller, group pathologist, Preston Royal Infirmary, for the results of the haematological investigations and the initial bacteriological findings.

\section{REFERENCES}

Barrow, G. I., and Peel, M. (1965). Mth. Bull. Minist. Hlth lab. Serv., $24,21$.

Bradstreet, C. M. P. (1965). Personal communication.

Castaneda, M. R., and Carrillo-Cardenas, C. (1953). Amer. J. med. Sci., 226, 504.

- and Ibarra, G. G. (1952). Antibiot. and Chemother., 2, 86.

Dalrymple-Champneys, W. (1960). Brucella Infection and Undulant Fever in Man, p. 96. Oxford University Press, London.

Debono, J. E. (1949). Lancet, 2, 326.

Eisele, C. W., and McCullough, N. B. (1947). J. Amer. med. Ass., 135, 1053.

Evans, A. C. (1934). J. Amer. med. Ass., 103, 665.

Huddleston, I. F. (1943). Brucellosis in Man and Animals, p .32. The Commonwealth Fund, New York.

Knight, V. (1950). Ann. N.Y. Acad. Sci., 53, 332.

Knight, V., Ruiz-Sanchez, F., and McDermott, W. (1950). Amer. J. med. Sci., 219, 627.

Mair, N. S. (1955). Mth. Mull. Minist. Hlth lab. Serv., 14, 184.

Report (1964a). Wld Hlth Org. tech. Rep. Ser., 289.

Report (1964b). Animal Diseases Survey. Report No. 4. Brucellosis in the British Dairy Herd. H.M. Stationery Office, London.

Robertson, L. (1961). Roy. Soc. Hlth J., 81, 46.

Spink, W. W. (1956a). The Nature of Brucellosis, p. 206. The University of Minnesota Press, Minneapolis. (1956b). Ibid., p. 200.

—, Hall, W. H., Shaffer, J. M., and Bruade, A. I. (1948). J. Amer med. Ass., 136, 382

Wilson, G. S. (1933). J. Hyg. (Lond.), 33, 516. 